\title{
Endodontic Management of C-shaped Root Canal System of Mandibular First Molar by using a modified Technique of Self-adjusting File System
}

\author{
Dilek Helvacioglu-Yigit
}

\begin{abstract}
Aim: C-shaped canal system is a seldom-found root canal anatomy which displays a challenge in all stages of endodontic treatment. According to the literature, this type of canal morphology is not a common finding in the mandibular first molar teeth.
\end{abstract}

Background: This case report presents endodontic management of a mandibular first molar with a $\mathrm{C}$-shaped canal system.

Case report: Root canal system was cleaned and shaped by nickel-titanium (NiTi) rotary instruments combined with selfadjusting file (SAF). Obturation was performed using warm, vertical condensation combined with the injection of warm gutta-percha. Follow-up examination 12 months later showed that the tooth was asymptomatic. The radiological findings presented no signs of periapical pathology.

Clinical significance: The clinician must be aware of the occurence and complexity of $\mathrm{C}$-shaped canals in mandibular first molar teeth to perform a successful root canal treatment. The supplementary use of SAF after application of rotary instruments in $\mathrm{C}$-shaped root canals might be a promising approach in endodontic treatment of this type of canal morphology.

Keywords: Dental anomalies, Root canal treatment, Rotary endodontics.

How to cite this article: Helvacioglu-Yigit D. Endodontic Management of C-shaped Root Canal System of Mandibular First Molar by using a modified Technique of Self-adjusting File System. J Contemp Dent Pract 2015;16(1):77-80.

Source of support: Nil

Conflict of interest: None declared

\section{INTRODUCTION}

C-shaped canal was first introduced by Cooke and Cox in 1979 to describe the cross-sectional morphology of the root resembling the letter ' $\mathrm{C}^{\prime}$. ${ }^{1}$ The characteristic feature is the connection of the root canals by a fin or web to form a ' $\mathrm{C}^{\prime}$ shape at the root canal orifice. ${ }^{2}$

Department of Endodontics, Dentistry Faculty, Kocaeli University, Kocaeli, Turkey

Corresponding Author: Dilek Helvacioglu-Yigit, Assistant Professor, Department of Endodontics, Dentistry Faculty Kocaeli University, Kocaeli Turkey, Phone: 905325267608 e-mail: dhelvacioglu@gmail.com
C-shaped canal is a seldom found root canal morphology. Studies report the frequency between 2.7 and $8 \%{ }^{3}$ Variations of root canal anatomy between races is reported in many studies. ${ }^{4-6}$ Investigations on the prevalence of C-shaped canal configuration show that C-shaped canals are more frequently seen in Asians than in other races ${ }^{5,7,8}$.

The diagnosis of C-shaped canals is challenging. Preoperative radiographs may remain ineffective in recognition of C-shaped canals. ${ }^{9}$ They are mostly recognized during access cavity preparation. Particular attention must be devoted to recognize the unusual anatomy of the C-shaped canal system. The complexity of the C-shaped canal system presents difficulties at shaping and obturation stages. ${ }^{9}$ Usage of manual stainless steel K-files can lead to procedural errors despite removal of a considerable percentage of area from canal walls. ${ }^{10}$ The rotary nickel-titanium (NiTi) instruments might be ineffective when dealing with C-shaped canals. ${ }^{10,11}$ The self-adjusting file (SAF) system (ReDent-Nova, Ra'anana, Israel) was recently introduced, with the intention of keeping the natural shape of the root canal. The vibrating metal lattice of the file adapts itself to the canal walls, even in oval-shaped or C-shaped canals. ${ }^{11,12}$

A high prevalence of this anatomical variation was reported in mandibular second molars. ${ }^{13}$ It may also be seen in mandibular first molars with a less common occurrence. ${ }^{14}$ To the best of our knowledge, only a few case reports in mandibular first molar with C-shaped morphology have been reported in the literature. ${ }^{15-17}$ This case report presents the endodontic management of a mandibular first molar tooth with C-shaped canal morphology.

\section{CASE REPORT}

A 20-year-old female patient attended the endodontic clinic at Kocaeli University, faculty of dentistry complaining of recurrent pain of the mandibular right first molar. Clinical examination revealed the presence of a deep dentinal caries lesion. The tooth was tender to percussion. There was no mobility. A orthopantomograph (panoramic radiograph) revealed that the patient 
had two unerupted supernumerary premolars in the mandibular arch (Fig. 1A). Radiographic examination showed a mandibular, first molar tooth with two roots close together (Fig. 1B). The contralateral tooth displayed the same radiographic configuration. After anesthesia was obtained, a rubber dam was placed. The access cavity was opened, and a continuous C-shaped, type I, canal orifice was observed (Fig. 2). ${ }^{18}$ Two initial files were inserted at the two ends of the C-shaped orifice, and an additional third file at the middle. Working length was determined using an apex locator (Raypex 5, VDW, Munich, Germany) and confirmed by a periapical radiograph (Fig. 1C). The radiographic image revealed that the file at the middle merged with the file at the distal canal which was relating to the type I (merging type) radiographic classification according to Fan et al. ${ }^{19}$ The canals were prepared by using Protaper Univesal (PTU) rotary instruments (Dentsply Maillefer, Ballaigues, Switzerland) supplemented with SAF system. First, the canals were prepared with PTU to the F2 file. SAF system was used to clean the recesses and isthmuses of the C-shaped canal system. Irrigation was copious throughout with a $2.5 \%$ sodium hypochlorite solution and ethylenediaminetetraacetic acid (EDTA) (MDChelCream, Meta Biomed, Chungbuk, Korea) was used for chelation. Calcium hydroxide dressing was applied between appointments. The complex root canal system was obturated with warm, vertical condensation and injected gutta-percha using BeeFill 2 in 1 (VDW, Munich, Germany) (Fig. 1D). AHPlus (Dentsply DeTrey, Konstanz, Germany) was used as root canal sealer. The tooth was permanently restored with a composite filling (Clearfil Majesty Posterior, Kuraray Medical Inc., Japan). Follow-up examination 12 months later showed that the tooth was asymptomatic. The radiological findings presented no signs of periapical pathology (Fig. 1E).

\section{DISCUSSION}

C-shaped root canal morphology is mostly found in mandibular second molar teeth. Reports presenting this type of canal morphology occurence in mandibular first molar teeth are extremely rare. ${ }^{15-17}$ In a study conducted
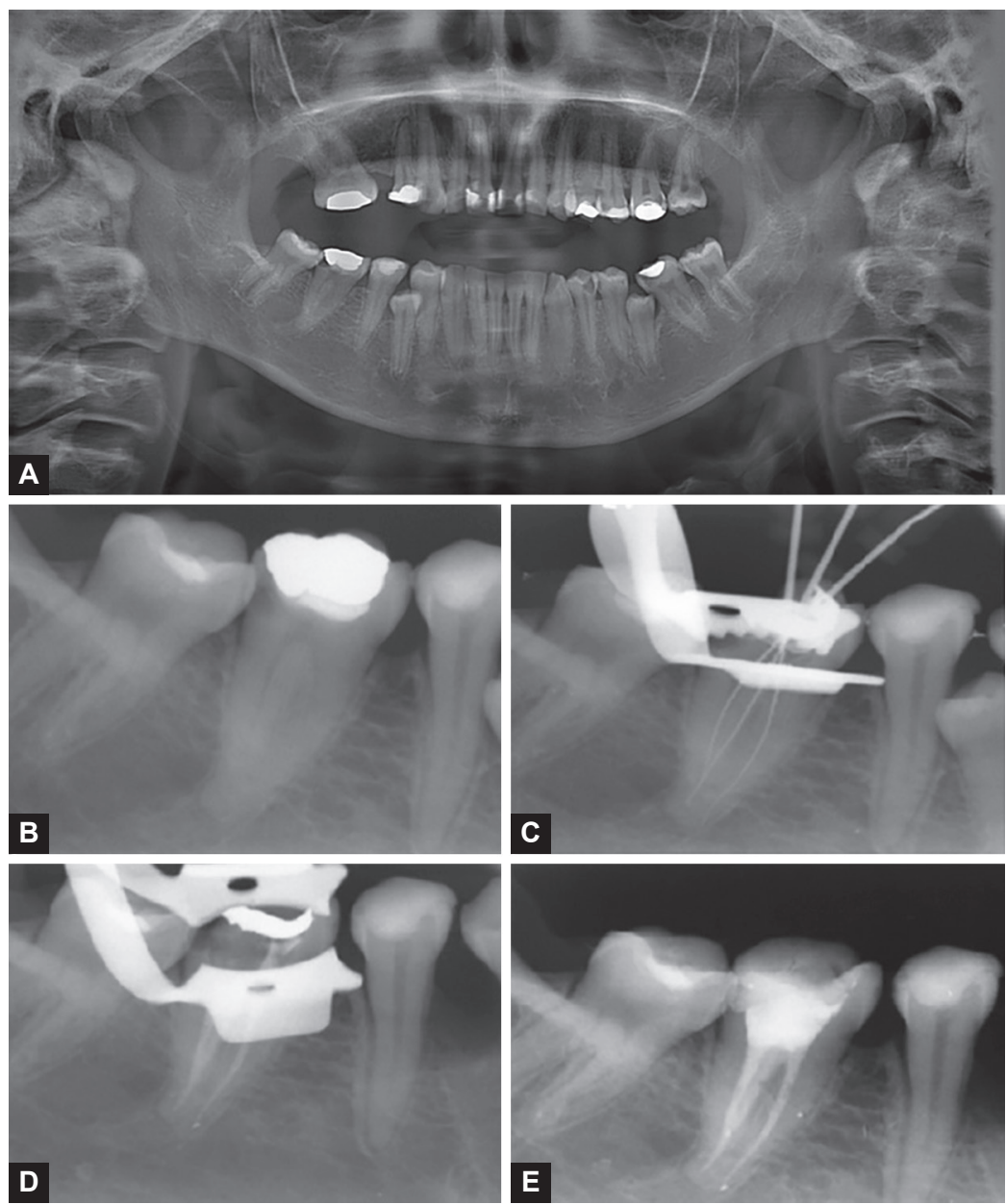

Figs $1 \mathrm{~A}$ to $\mathrm{E}$ : Panoramic and periapical radiographs of mandibular right first molar tooth: (A) preoperative panoramic image showing bilateral mandibular first molar teeth with fused roots, (B) preoperative radiograph of mandibular right first molar with caries, (C) Radiograph taken for working length determination. Note: the mesiobuccal canal and distal canal merging in middle third of distal root to form one foramina at the apex, (D) Obturation of the root canal system and (E) 12 months postoperative follow-up radiograph 
on a group of Turkish inhabitants, the prevalence of C-shaped root canals in mandibular second molars was found to be $8.9 \% .^{20}$ However, previous studies reported that C-shaped canal morphology was not observed in mandibular first molars in the same population. ${ }^{21,22}$ In the present case report, a C-shaped root canal morphology occurence in a mandibular first molar and its endodontic treatment were described.

It is hard to identify a C-shaped canal system in radiographic examination. This complex system is commonly recognized only during access cavity preparation. Anatomical configuration of C-shaped canals may vary along the length of the root where recesses, fins, anastomoses and isthmuses make the cleaning and shaping of the root canal system difficult to accomplish. ${ }^{11}$ When such a canal system is first recognized, additional endodontic instruments might be advantageous in dealing with its complex anatomy. Use of ultrasonics for irrigation may facilitate the infected tissue debris removal from the recesses and fins of the canal systems. ${ }^{23}$ A recentlyintroduced SAF system shapes the root canal with an adaptation to the canal walls to remove a uniform layer of dentin additional to its irrigation effect. Solomonov et $\mathrm{al}^{11}$ found the SAF system more effective than the rotary NiTi instruments in shaping the walls of C-shaped root canals. Yin et $\mathrm{al}^{24}$ reported that a large proportion of canal surface remained untouched in C-shaped root canals regardless of the instrumentation technique used. This was related to tiny isthmus areas in which rotary or hand instruments could hardly be inserted..$^{10}$ In the present case report, rotary instruments were combined with the SAF system instead of ultrasonic irrigation to obtain better debridement. This is the first case report describing the management of a C-shaped mandibular molar combining two techniques.

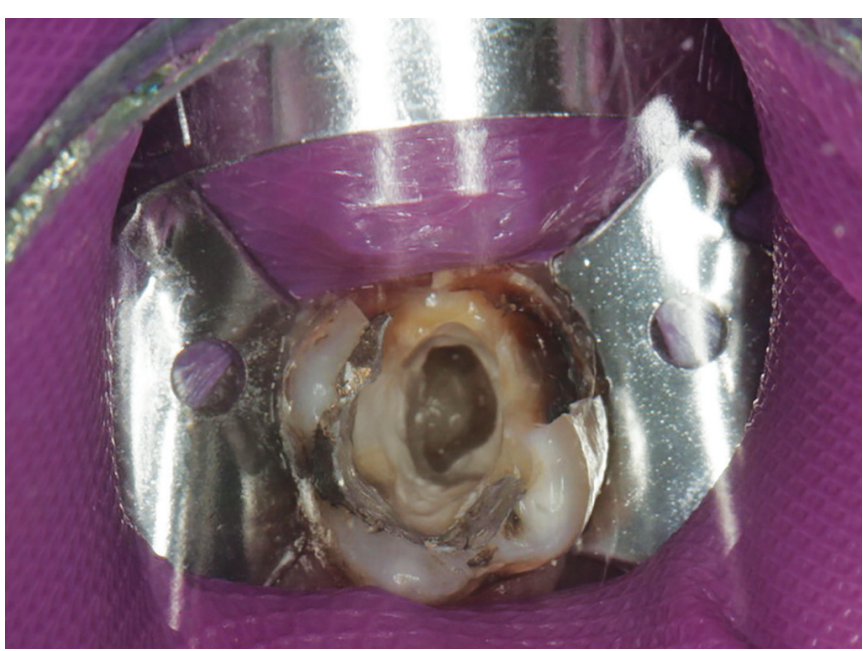

Fig. 2: Clinical photograph of the access cavity and C-shaped orifice of the root canal

\section{CLINICAL SIGNIFICANCE}

The clinician must be aware of the occurrence and complexity of C-shaped canals in mandibular first molar teeth to perform a successful root canal treatment. The supplementary use of SAF after application of rotary instruments in C-shaped root canals might be a promising approach in endodontic treatment of this type of canal morphology.

\section{REFERENCES}

1. Cooke HG, 3rd, Cox FL. C-shaped canal configurations in mandibular molars. J Am Dent Assoc 1979;99(5):836-839.

2. Fan B, Cheung GS, Fan M, Gutmann JL, Bian Z. C-shaped canal system in mandibular second molars: Part IAnatomical features. J Endod 2004;30(12):899-903.

3. Jafarzadeh $\mathrm{H}, \mathrm{Wu} \mathrm{YN}$. The C-shaped root canal configuration: a review. J Endod 2007;33(5):517-523.

4. Haddad GY, Nehme WB, Ounsi HF. Diagnosis, classification, and frequency of C-shaped canals in mandibular second molars in the Lebanese population. J Endod 1999;25(4): 268-271.

5. Zheng Q, Zhang L, Zhou X, Wang Q, Wang Y, Tang L, Song F, Huang D. C-shaped root canal system in mandibular second molars in a Chinese population evaluated by cone-beam computed tomography. Int Endod J 2011;44(9):857-862.

6. Al-Fouzan KS. C-shaped root canals in mandibular second molars in a Saudi Arabian population. Int Endod J 2002;35(6):499-504.

7. Seo MS, Park DS. C-shaped root canals of mandibular second molars in a Korean population: clinical observation and in vitro analysis. Int Endod J 2004;37(2):139-144.

8. Jin GC, Lee SJ, Roh BD. Anatomical study of C-shaped canals in mandibular second molars by analysis of computed tomography. J Endod 2006;32(1):10-13.

9. Melton DC, Krell KV, Fuller MW. Anatomical and histological features of C-shaped canals in mandibular second molars. J Endod 1991;17(8):384-388.

10. Yin XZ, Cheung GSP, Zhang CF, Masuda YM, Kimura Y, Matsumoto K. Microcomputed tomographic comparison of nickel-titanium rotary versus traditional instruments in C-shaped root canal system. J Endod 2010;36(4):708-712.

11. Solomonov M, Paque F, Fan B, Eilat Y, Berman LH. The challenge of C-shaped canal systems: a comparative study of the self-adjusting file and ProTaper. J Endod 2012;38(2):209-214.

12. Metzger Z, Teperovich E, Zary R, Cohen R, Hof R. The selfadjusting file (SAF). Part 1: respecting the root canal anatomy: a new concept of endodontic files and its implementation. J Endod 2010;36(4):679-690.

13. Manning SA. Root canal anatomy of mandibular second molars. Part II. C-shaped canals. Int Endod J 1990;23(1):40-45.

14. dePabloOV,Estevez R, Peix SanchezM,Heilborn C,Cohenca N. Root anatomy and canal configuration of the permanent mandibular first molar: a systematic review. J Endod 2010;36(12):1919-1931.

15. Bolger WL, Schindler WG. A mandibular first molar with a C-shaped root configuration. J Endod 1988;14(10):515-519.

16. Rice RT, Gilbert BO Jr. An unusual canal configuration in a mandibular first molar. J Endod 1987;13(10):515-515.

17. Fabra-Campos H. Unusual root anatomy of mandibular first molars. J Endod 1985;11(12):568-572. 
18. Min Y, Fan B, Cheung GS, Gutmann JL, Fan M. C-shaped canal system in mandibular second molars Part III: The morphology of the pulp chamber floor. J Endod 2006;32(12):1155-1159.

19. Fan B, Cheung GS, Fan M, Gutmann JL, Fan W. C-shaped canal system in mandibular second molars: Part IIRadiographic features. J Endod 2004;30(12):904-908.

20. Helvacioglu-Yigit D, Sinanoglu A. Use of cone-beam computed tomography to evaluate C-shaped root canal systems in mandibular second molars in a Turkish subpopulation: a retrospective study. Int Endod J 2013;46(11):1032-1038.

21. Miloglu O, Arslan H, Barutcigil C, Cantekin K. Evaluating root and canal configuration of mandibular first molars with cone beam computed tomography in a Turkish population. Journal of Dental Sciences 2013;8(1):80-86.

22. Sert S, Bayirli GS. Evaluation of the root canal configurations of the mandibular and maxillary permanent teeth by gender in the Turkish population. J Endod 2004;30(6):391-398.

23. Cheung LH, Cheung GS. Evaluation of a rotary instrumentation method for C-shaped canals with micro-computed tomography. J Endod 2008;34(10):1233-1238.

24. Yin X, Cheung GS, Zhang C, Masuda YM, Kimura Y, Matsumoto K. Microcomputed tomographic comparison of nickel-titanium rotary versus traditional instruments in C-shaped root canal system. J Endod 2010;36(4):708-712. 